\title{
УДК 389536.5:121.383.8
}

\section{А.Г. ШАЙКО-ШАЙКОВСКИЙ}

\section{Методика оценки собственных частот колебаний систем с несколькими степенями свободы на примере термоэлектрических охладителей}

\author{
Аннотация. Предложена методика определения собственных частот колебаний \\ термоэлектрических охладителей (ТЭО) - многокаскадных изделий этажерочного типа \\ путем использования уравнений Лагранжа II-го рода. \\ Ключевые слова: собственные частоты колебаний, резонанс, демпфирование. \\ Abstract. It was proposed a method of definition of natural frequencies of the multi-cascade \\ products through the use of Lagrange equation of second kind. \\ Keywords: natural frequencies, resonance, damping. \\ DOI: 10.31649/1681-7893-2019-37-1-104-108
}

\section{ВВЕДЕНИЕ}

В состав целого ряда приборов, измерительных средств, электронных устройств и систем с целью охлаждения отдельных радиоэлементов и обеспечения нормальных условий их работы, для уменьшения веса и габаритов аппаратуры часто вводятся термоэлектрические охладители (ТЭО), работа которых базируется на известном принципе Пельтье. При этом в зависимости от специфики и параметров электронных устройств, их мощности, величины выделяемой тепловой энергии и назначения используются ТЭО с различным числом каскадов. Аналогичные изделия, в которых используется обратный эффект, применяются в бесконтактных дистанционных регистраторах и измерителях температуры (например, в электронных измерительных приборах, в медицине - при диагностике воспалительных процессов).

Ниже на рис. 1 представлен общий вид, 3-х каскадной конструкции ТЭО.

Число термоэлементов для рассматриваемого конкретного случая в каскадах исследуемых в работе изделий составляло: $n_{1}=12, n_{2}=22, n_{3}=52, n_{4}=128$ (на рис. 2 в качестве примера показан 3 -х каскадный охладитель). Длина каждого термоэлемента во всех каскадахсоставляла $l=1,4$ мм; размеры поперечного сечения термоэлементов: $0,7 \times 0,7$ мм. Материал, из которого изготовлены термоэлементы, - теллурид

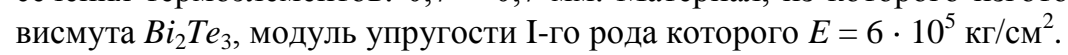

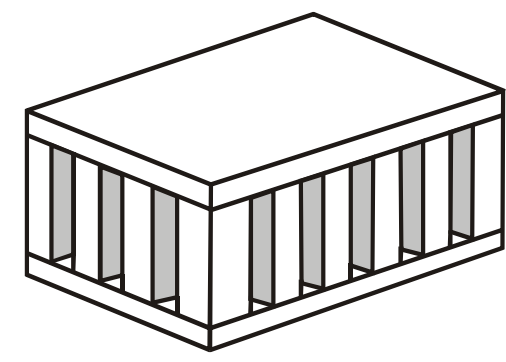

a)

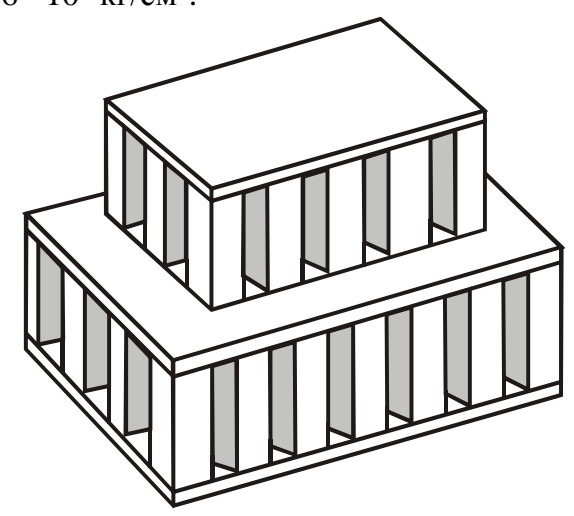

б)

Рис.1. Общий вид одно и двухкаскадного ТЭО

( ) А.Г. ШАЙКО-ШАЙКОВСКИЙ, 2019 
На рис. 1 показан общий вид одно- и двух каскадных ТЭО. Структурно такой прибор представляет собой этажерочную конструкцию, которая сосотоит из теплопереходов, изготовленных из ситалла и термоелементов в виде паралелепипедов. Термоелементы изготовлены из монокристалла $\mathrm{Bi}_{2} \mathrm{Te}_{3}$. Для их соединения используется медная коммутационная дорожка, которая нанесена на поверхность теплоперехода. Перепад температур $\Delta \mathrm{T}$ возникает вследствие действия эффекта Пельтьє. Для усиления сигнала в каждом каскаде используется нужное определённое количество термоелементов.

2

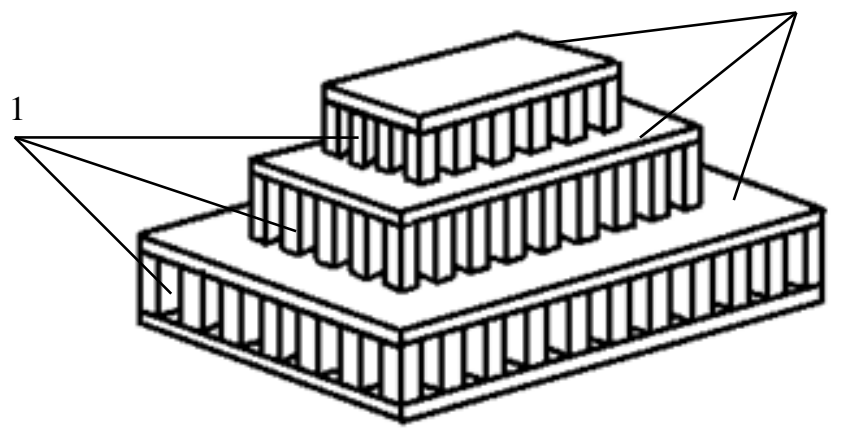

Рис.2. Общий вид 3-х каскадной конструкции:

(1 - термоэлементы; 2 - теплопереходы)

Теплопереходы, как правило, изготовливлены из ситалловых пластин толщиной 0,1 мм с нанесенными на них медными токопроводящими коммутационными дорожками. Массы теплопереходов при указанном выше числе термоэлементов составляли: $m_{1}=10,92896 \cdot 10^{-5} \kappa 2 ; m_{2}=4,55961 \cdot 10^{-5} \kappa 2 ; m_{3}$ $=1,95753 \cdot 10^{-5} \kappa 2 ; m_{4}=1,31891 \cdot 10^{-5} \kappa 2$. Для крепления термоэлементов к токопроводящей дорожке на боковой поверхности теплопереходов применялся припой, толщина которого составляет $\Delta=1 \cdot 10^{-1} \mathrm{Mм}$, (модуль упругости I-го рода припоя принят $E_{\Pi}=1,2 \cdot 10^{5}$ кг $/ \mathrm{cm}^{2}$ ).

Такие изделия, применяемые в электронной аппаратуре, часто называемые микрохолодильниками, несмотря на их небольшие габариты и массу позволяют достичь перепада температур до $20{ }^{0} \mathrm{C}$ на каждом из каскадов прибора, что дает возможность довольно существенно охлаждать работающие в различных устройствах электронные системы и изделия. Установка подобных ТЭО на различного рода подвижных аппаратах (наземных, надводных, подводных, авиационных, космических) позволяет существенно уменьшить общий вес радиоэлектронной аппаратуры, ее габариты и материалоёмкость, и увеличить, тем самым, вес полезной нагрузки.

Как известно, работа любого устройства и конструкции носителя характеризуется определенной частотой и амплитудой вынуждающих колебаний, которые в совокупности генерируются установленной на нем аппаратурой, двигателями и другими устройствами. Обеспечение нормальной работы, в частности, ТЭО, их механической целостности сопряжено с недопущением возможности возникновения явления резонанса при воздействии на них определенных спектров частот вынуждающих колебаний [1].

Поэтому, определение собственных частот колебаний изделий еще на этапе их проектирования важная и актуальная инженерно-техническая задача. Для этого, кроме экспериментальных методов, используется математическое моделирование, которое позволяет при использовании моделей разной сложности с требуемой для каждой конкретной задачи точностью определить искомые проектные параметры [2].

Определение собственных частот колебаний ТЭО, имеющих структуру этажерочных конструкций осуществлялось с помощью математической модели, базирующейся на использовании дифференциальных уравнений Лагранжа II-го рода [3]:

$$
\frac{d}{d t}\left(\frac{\partial T}{\partial \dot{x}_{i}}\right)-\frac{\partial T}{\partial x_{i}}=-\frac{\partial \Pi}{\partial x_{i}}-\frac{\partial \Phi}{\partial \dot{x}_{i}},
$$

где: $T$ - кинетическая энергия системы, $\Pi$ - потенциальная энергия системы, $i$ - обобщенная координата, $x_{i}$ - перемещение $i$-го каскада $(i=1,2,3,4), \Phi$ - диссипативная функция, $t$ - время.

Кинетическая энергия системы:

$$
T=\sum_{i=1}^{4} T_{i}
$$


Потенциальная энергия системы:

$$
\Pi=\sum_{i=1}^{4} \ddot{I}_{i}
$$

Диссипативная функция пропорциональна скорости перемещения центра масс системы:

$$
\begin{aligned}
\Phi & =\sum_{i=1}^{4} \hat{O}_{i}, \\
\Phi_{i} & =\frac{1}{2} \beta_{i} \dot{x}_{i}^{2},
\end{aligned}
$$

где $\beta_{i}-$ коэффициент затухания.

В работе рассмотрен конкретный случай исследования 4-х каскадного ТЭО $(i=1,2,3,4)$, который схематически можно изобразить в виде, представленном на рисунке 2.

Здесь в качестве $m_{i}$ берутся массы соответствующих теплопереходов, а в качестве $c_{i}-$ жесткости соответствующих термоэлементов каждого каскада [2].

Слои припоя по торцам термоэлемента имеют значения модуля упругости I-го рода существенно ниже чем аналогичный параметр материала самих термоэлементов, т.е. характеризуются меньшей жесткостью. Поэтому можно считать, что слои припоя по торцам термоэлементов в каждом каскаде выполняют роль своеобразных демпферов, снижающих значения собственных колебаний изделия.

a)
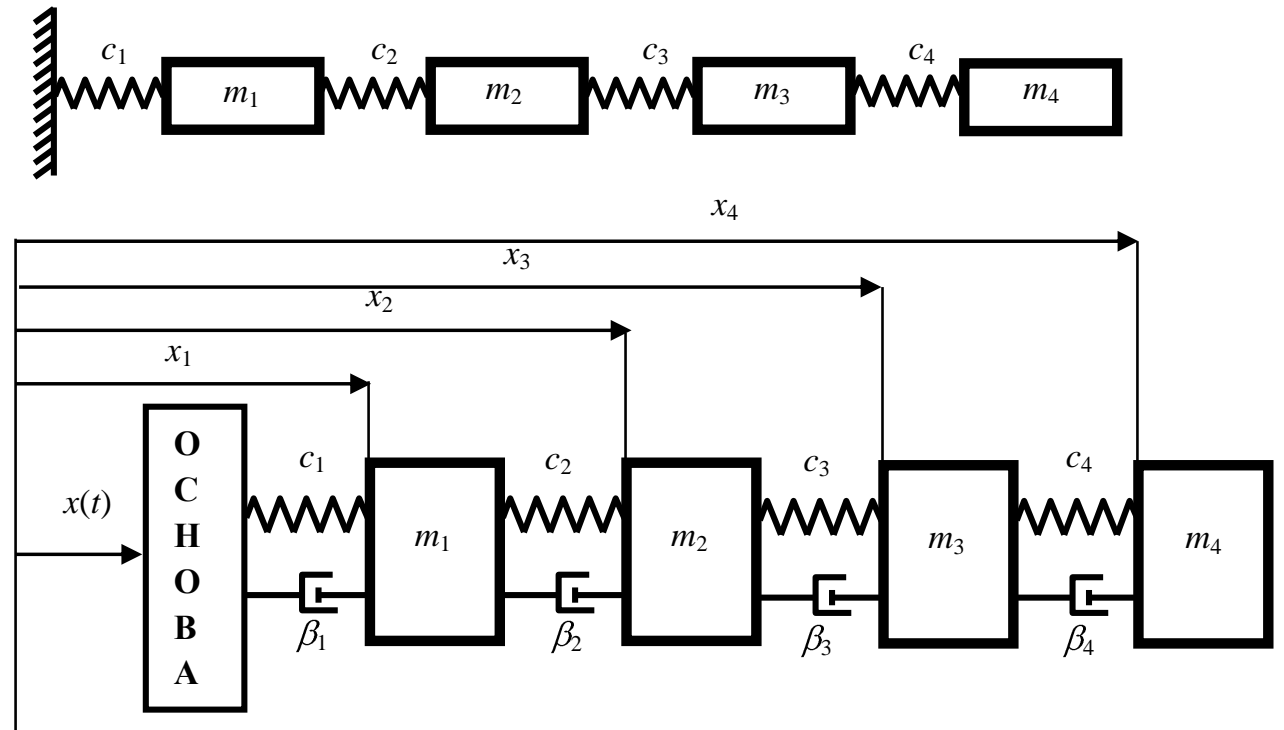

Рис.3. Расчетная схема четырехкаскадного изделия:

а) без учета демпфирования; б) с учетом демпфирования

Как известно - диссипативная функция носит нелинейный характер [5]. Учет этой нелинейности в сложных технических системах сопряжен со значительными, в том числе математическими трудностями, но во многих случаях может внести определенные уточнения в значениях отыскиваемых величин параметров с учетом специфики изделия и условий их эксплуатации.

В связи с малыми размерами исследуемых изделий, габаритами и спецификой их использования, в работе принято допущение о том, что на проектном этапе исследований величину диссипативных сил можно не учитывать. (Это допущение проверено расчетным путем на примере 1-но каскадного изделия, значения собственных частот колебаний которого определялись как с учетом диссипативной функции, так и без нее. Расхождения значений полученных результатов не выходило за пределы 5\%).

Рассмотрена приближенная математическая модель для 2-х, 3-х и 4-х каскадных ТЭО, для чего была использована специально разработанная программа, что позволило определить значения частот собственных колебаний, как для рассмотренных случаев конструктивного выполнения изделий, так и для любой иной численности термоэлементов в каждом каскаде. При этом проанализировано влияние толщины слоев припоя на величины собственных частот колебаний, которые определены также и для случая отсутствия демпфирования. Рассмотрены случаи различного сочетания разного числа термоэлементов в каждом каскаде, а также случай, когда жесткость всех каскадов одинакова. Проведенные исследования позволили установить зависимости изменения значений собственных частот колебаний от наличия демпферов, их параметров, а также - от характеристик жесткости каждого каскада. 
Полученные результаты позволяют еще на этапе проектирования и разработки будущих изделий предусмотреть случай резонанса систем, принять меры по «уводу» собственных значений колебаний изделий в сторону от значений резонансных частот. Это особенно важно при разработке систем, работающих на подвижных носителях, имеющих определенные заранее известные значения вынужденных колебаний.

Полученные результаты для удобства анализа содержатся в таблицах $1-4$.

Таблица 1

Значения собственных частот колебаний 3 -х каскадного изделия при $n_{1}=124$, $n_{2}=54, n_{3}=24$ с учетом демпфирования (Гц)

\begin{tabular}{|c|c|c|c|}
\hline Количество термоэлементов & 124 & 54 & 24 \\
\hline $\begin{array}{c}\text { Значения собственных частот, полученные } \\
\text { с помощью дифференциальных уравнений } \\
\text { Лагранжа IІ-го рода }\end{array}$ & $2,177 \cdot 10^{4}$ & $4,027 \cdot 10^{4}$ & $5,50 \cdot 10^{4}$ \\
\hline
\end{tabular}

Таблица 2

Значения собственных частот колебаний 3 -х каскадного изделия при $n_{1}=124, n_{2}=54, n_{3}=24$ без учета демпфирования (Гц)

\begin{tabular}{|c|c|c|c|}
\hline Количество термоэлементов & 124 & 54 & 24 \\
\hline $\begin{array}{c}\text { Значения собственных частот колебаний, } \\
\text { полученные с помощью } \\
\begin{array}{c}\text { дифференциальных уравнений Лагранжа } \\
\text { ІІ-го рода }\end{array}\end{array}$ & $2,949 \cdot 10^{6}$ & $5,455 \cdot 10^{6}$ & $7,45 \cdot 10^{6}$ \\
\hline
\end{tabular}

Данные таблиц 1 и 2 свидетельствует о том, что разброс собственных частот зависит от количества элементов в каскаде и меняется в пределах 1,94\% - 4,51\% - для изделий с учетом демпфирования и, соответственно, в пределах 5,27\% - 5,19\% - для изделий без учета демпфирования (при уменьшении количества термоэлементов в каскаде в обоих случаях расхождение возрастает).

Таблица 3

Значения собственных частот колебаний для системы с 4-ю ступенями свободы с учетом демпфирования (Гц)

\begin{tabular}{|c|c|c|c|c|}
\hline Количество термоэлементов & 124 & 54 & 24 & 12 \\
\hline $\begin{array}{c}\text { Значение собственных частот, } \\
\text { полученные с помощью } \\
\begin{array}{c}\text { дифференциальных уравнений } \\
\text { Лагранжа ІІ-го рода }\end{array}\end{array}$ & $1,797 \cdot 10^{4}$ & $3,187 \cdot 10^{4}$ & $4,682 \cdot 10^{4}$ & $5,741 \cdot 10^{4}$ \\
\hline
\end{tabular}

Данные таблиц 3, 4 свидетельствует, что разброс значений собственных частот колебаний, полученный двумя независимыми путями с учетом демпфирования лежит в границах 2,44\% - 2,91\%, а при условии, что демпфирование не учитывается, эти значения будут 6,49\% - 5,58\%.

Таблица 4

Значения собственных частот колебаний для системы с 4-ю ступенями свободы без учета демпфирования (Гц)

\begin{tabular}{|c|c|c|c|c|}
\hline Количество термоэлементов & 124 & 54 & 24 & 12 \\
\hline $\begin{array}{c}\text { Значения собственных частот, } \\
\text { полученные с помощью } \\
\begin{array}{c}\text { дифференциальных уравнений } \\
\text { Лагранжа II-го рода }\end{array}\end{array}$ & $2,434 \cdot 10^{6}$ & $4,318 \cdot 10^{6}$ & $6,344 \cdot 10^{6}$ & $7,774 \cdot 10^{6}$ \\
\hline
\end{tabular}

Анализ полученных расчетным путем результатов позволяет еще на этапе проектирования оценить величины значений собственных частот колебаний конкретных, используемых на практике изделий ТЭО.

Разработанные программы расчетов на персональных компьютерах позволяют определить собственные частоты колебаний ТЭО различных конфигураций с разными вариантами конструктивного выполненения, оценить целесообразность применения различных вариантов конструктивного выполнения проектируемых изделий, определить наиболее приемлемый вариант конфигурации конструкции ТЭО для каждого типа носителя аппаратуры. 


\section{ЛИТЕРАТУРА}

1. Клепиковский А.В., Тимофеева Е.Н., Шайко-Шайковский А.Г. Уточнённая математическая модель оценки собственных частот колебаний систем с несколькими степенями свободы/ Материалы Международного симпозиума «Надёжность и качество-2011», Пенза, Россия, 2011, 25-31 мая. С. 305-307.

2. Клепиковский А.В., Тимофеева Е.Н., Шайко-Шайковский А.Г. Математическая модель оценки факторов, влияющих на значения собственных частот колебаний систем с несколькими степенями свободы // Труды междунар. симп. «Надежность и качество 2009», (Пенза, 25-30 мая 2009 г.). - Т. 1. - С. 300-302.

3. Вибрации в технике. Справочник. Т. 3. Колебания машин, конструкций и их элементов / [под ред. Ф.М. Диментберга, К.С. Колесникова]. - М.: Машиностроение, 1980. - 544 с.

4. Методы определения характеристик демпфирования колебаний упругих систем / Писаренко Г.С., Матвеев В.В., Яковлев А.Н. - К.: Наукова думка, 1976. - 86 с.

5. Вибрации в технике. Справочник в 6 т. Т. 6. Защита от вибрации и ударов / [под ред. К.В. Фролова]. - М.: Машиностроение, 1981. - 456 с.

6. Клепіковський А.В., Тимофієва Є.М., Царик Т.О., Шайко-Шайковський О.Г.

7. Методика визначення власних частот коливань термоелектричних охолоджувачів за допомогою математичного моделюванняВісник мельницького національного університету. №4 2005. Ч.1.т.2. - c.209-215.

Пришла в редакцию: 16.04.2019

ШАЙКО-ШАЙКОВСКИЙ АЛЕКСАНДР ГЕННАДЬЕВИЧ - профессор, доктор технИческИХ наук, Черновицкий национальный университет, Черновцы, Украина. 